\title{
Eigenlijke (wettelijke) en oneigenlijke (contractuele) lossing
}

\author{
Prof. mr. N.E.D. Faber en mr. N.S.G.J. Vermunt*
}

\section{Inleiding}

In 1997 besteedde Faber in de kolommen van dit blad aandacht aan de eigenlijke (wettelijke) lossing van een met pand of hypotheek bezwaard goed op de voet van art. 58 lid 2 van de Faillissementswet $(\mathrm{Fw})$, en aan de in de praktijk daarop ontwikkelde variant van de oneigenlijke (contractuele) lossing. ${ }^{1}$ Twee recente arresten van de Hoge Raad geven aanleiding om nogmaals aandacht te vragen voor dit onderwerp.

\section{Lossing van verpande of verhypothekeerde goederen}

Bij de eigenlijke lossing van een met pand of hypotheek bezwaard goed gaat het om de voldoening van de pand- of hypotheekhouder uit tot de boedel behorend actief, waarna het desbetreffende goed onbezwaard in de boedel terugkeert, en door de curator op de voet van art. 101 of art. $176 \mathrm{Fw}$ wordt geëxecuteerd. Het pand- of hypotheekrecht gaat als gevolg van de voldoening van de pand- of hypotheekhouder, en niet als gevolg van de executie, teniet. Deze eigenlijke lossing sluit aan bij de lossing door de pand- of hypotheekgever zelf op de voet van art. 3:249 lid 2 respectievelijk art. 3:269 van het Burgerlijk Wetboek (BW). In geval van een oneigenlijke lossing wordt het bezwaarde goed niet daadwerkelijk door de curator ingelost, maar wordt het door hem geëxecuteerd, waarna de pand- of hypotheekhouder (zonder in de omslag van de algemene faillissementskosten te worden betrokken, maar met inachtneming van een boedelbijdrage) wordt voldaan uit de opbrengst van het desbetreffende goed. Bij oneigenlijke lossing gaat een hypotheekrecht teniet door zuivering (art. $188 \mathrm{Fw}$ ) en een pandrecht doordat daarvan door de pandhouder afstand wordt gedaan (art. 3:258 lid 2 BW). Het verschil tussen eigenlijke en oneigenlijke lossing is dat de volgorde van de te verrichten handelingen wordt omgekeerd. Bij een eigenlijke lossing wordt de pand- of hypotheekhouder eerst voldaan en wordt daarna het ingeloste (onbezwaarde) goed uitgewonnen; bij een oneigenlijke lossing wordt het des-

\footnotetext{
Prof. mr. N.E.D. Faber is hoogleraar burgerlijk recht aan de Radboud Universiteit Nijmegen, lid van het dagelijks bestuur van het Onderzoekcentrum Onderneming \& Recht, adviseur bij Clifford Chance en raadsheer-plaatsvervanger in het Gerechtshof Den Haag. Mr. N.S.G.J. Vermunt is secretaris van het Onderzoekcentrum Onderneming \& Recht van de Radboud Universiteit Nijmegen en adviseur bij Linklaters.

1. Vgl. N.E.D. Faber, Bodem(voor)recht versus stil pandrecht, JOR 1997/10, NbBW 1997, p. 14-18 en De positie van de tweede hypotheekhouder bij onderhandse executie door de eerste hypotheekhouder, NbBW 1997, p. 67-70.
}

betreffende goed eerst door de curator uitgewonnen en wordt de pand- of hypotheekhouder, die afziet van de uitoefening van zijn pand- of hypotheekrecht, uit de opbrengst van het goed voldaan als ware hij separatist. Beide vormen van lossing hebben met elkaar gemeen dat het pand- of hypotheekrecht niet wordt uitgeoefend en dat het desbetreffende goed door de curator op grond van zijn algemene bevoegdheid tot het te gelde maken van tot de boedel behorende activa wordt uitgewonnen. De oneigenlijke lossing berust op een overeenkomst tussen de curator en de pand- of hypotheekhouder en wordt daarom ook wel contractuele lossing genoemd. Alleen de eigenlijke lossing wordt in art. 58 lid $2 \mathrm{Fw}$ genoemd en wordt ook wel met de term wettelijke lossing aangeduid.

In de jurisprudentie van de Hoge Raad is de oneigenlijke lossing aanvaard. De Hoge Raad heeft haar bij herhaling met een eigenlijke lossing op één lijn gesteld. ${ }^{2}$

\section{Van oud naar nieuw}

Met het voorafgaande viel goed te werken. Decennialang vond een oneigenlijke lossing langs de hiervóór uiteengezette lijnen plaats. In het arrest ING/Hielkema q.q. ${ }^{3}$ breekt de Hoge Raad echter met het verleden en herkwalificeert hij een oneigenlijke lossing als de uitoefening door de curator in eigen naam van het aan de pandhouder toekomende recht van parate executie. De bevoegdheid daartoe ontleent de curator - aldus nog steeds de Hoge Raad - aan een overeenkomst tussen de curator en de pandhouder tot onderhandse executie op de voet van art. 3:251 lid $2 \mathrm{BW}$. In het verlengde hiervan overweegt de Hoge Raad dat een oneigenlijke lossing een vorm van executie door de pandhouder is, waarop art. $57 \mathrm{Fw}$ van toepassing is, terwijl een eigenlijke lossing op de voet van art. 58 lid $2 \mathrm{Fw}$ juist geschiedt ter voorkoming van de uitoefening van het recht van parate executie door de pandhouder. In de nieuwe benadering van de Hoge Raad zijn de eigenlijke en oneigenlijke lossing twee wezenlijk van elkaar verschillende figuren. Het is zelfs zinledig en verwarrend om nog van oneigenlijke lossing te spreken; wat eerst een oneigenlijke lossing was, is thans niets

2. Vgl. onder meer HR 1 september 1978, NJ 1980/345 (Lijzenga), HR 28 juni 1985, NJ 1985/887 (Lier q.q./NMB), HR 13 maart 1987, NJ 1988/556 (Ontvanger/Spruijt q.q.) en HR 3 december 1993, NJ 1994/176 (Glebbeek/Dijkstra q.q.). Vgl. ook (met betrekking tot verpande goederen) het feitencomplex dat aan het arrest van de Hoge Raad inzake Aerts q.q./ABN AMRO Bank (HR 26 juni 1998, JOR 1998/126) ten grondslag ligt.

3. HR 25 februari 2011, JOR 2014/271 m.nt. Faber en Vermunt. 
anders dan de uitoefening van het pandrecht, in casu door de curator in eigen naam ten behoeve van de pandhouder. Een vergelijkbare en op het arrest ING/Hielkema q.q. geënte redenering geeft de (fiscale kamer van de) Hoge Raad in de beschikking Staatssecretaris van Financiën/ $\mathrm{X}^{4}$ ter zake van de oneigenlijke lossing van een verhypothekeerd goed, gebaseerd op een overeenkomst tussen de curator en de hypotheekhouder. Volgens de Hoge Raad is ook in een dergelijk geval sprake van een onderhandse executoriale verkoop, in casu door de curator in eigen naam ten behoeve van de hypotheekhouder. Dat is op zijn zachtst gezegd opmerkelijk, aangezien niet wordt voldaan aan de vereisten die art. 3:268 lid $2 \mathrm{BW}$ aan een dergelijke executoriale verkoop (dwingendrechtelijk) stelt.

\section{De nieuwe benadering is vergezocht}

De opvatting van de Hoge Raad dat een onderhandse executoriale verkoop op de voet van art. 3:251 lid 2 BW kan plaatsvinden doordat de pandgever, c.q. de curator in het faillissement van de pandgever, in eigen naam het aan de pandhouder toekomende recht van parate executie uitoefent, is op zichzelf juist. ${ }^{5}$ Dat een oneigenlijke lossing van verpande goederen als een dergelijke vorm van uitwinning moet worden beschouwd, ligt echter niet erg voor de hand. De afspraken die partijen in de praktijk in het kader van een oneigenlijke lossing maken, wijzen in een geheel andere richting, en ook de Separatistenregeling (Recofa-richtlijnen, Bijlage E) staat ver af van de door de Hoge Raad gegeven kwalificatie van een oneigenlijke lossing. In dit verband moet worden bedacht - zoals wij hiervoor reeds hebben aangegeven - dat een oneigenlijke lossing geheel is gebaseerd op een overeenkomst tussen de curator en de pandhouder. Ligt het dan niet voor de hand dat partijen ook zelf (kunnen) bepalen op welke wijze zij de verkoop van de desbetreffende goederen vormgeven? De contractsvrijheid brengt zulks toch met zich? Indien de Hoge Raad heeft bedoeld dat een oneigenlijke lossing van verpande goederen uitsluitend op de voet van art. 3:251 lid 2 BW kan plaatsvinden, of dat iedere ter zake daarvan gemaakte afspraak tussen partijen op de door de Hoge Raad aangegeven wijze moet worden uitgelegd, is zulks onzes inziens (onnodig) rigide en onjuist.

\section{De nieuwe benadering is in strijd met de wet}

Ronduit problematisch wordt de nieuwe benadering van de Hoge Raad bij de oneigenlijke lossing van een met hypotheek bezwaard goed. Het lijkt erop dat de Hoge Raad zich bij het wijzen van het arrest ING/Hielkema q.q. niet bewust was van het feit dat er belangrijke verschillen bestaan tussen de uitwinning bij pand en hypotheek. Het ligt voor de hand dat een oneigenlijke lossing van een met hypotheek bezwaard goed op dezelfde wijze wordt geduid als een oneigenlijke lossing van een met pand bezwaard goed. Dat is in ieder geval decennia lang zo gebeurd en is in overeenstemming met de tussen partijen gemaakte afspraken, die bij pand en hypotheek niet wezen-

4. HR 15 maart 2013, JOR 2014/270 m.nt. Faber en Vermunt.

5. Vgl. ook HR 14 februari 2014, JOR 2014/118 m.nt. Faber en Schuijling (Feenstra q.q./ING). lijk van elkaar verschillen. Aan het slot van r.o. 3.4 van het arrest ING/Hielkema q.q., waar pand en hypotheek in één adem worden genoemd, lijkt ook de Hoge Raad daarvan uit te gaan. In de nieuwe benadering van de Hoge Raad leidt dit echter tot problemen, nu bij hypotheek een tegenhanger van art. 3:251 lid 2 BW ontbreekt. Wil men - zoals de Hoge Raad doet - een oneigenlijke lossing vormgeven als de uitoefening door de curator in eigen naam van het aan de hypotheekhouder toekomende recht van parate executie, dan is daarop art. 3:268 BW - met de in dat artikel opgenomen beperkingen van toepassing. De hypotheekhouder kan niet op een andere wijze dan in het artikel bepaald verhaal nemen op het verbonden goed, en een daartoe strekkend beding is nietig (art. 3:268 lid $5 \mathrm{BW}$ ). De wet voorziet - anders dan bij pand - niet in de mogelijkheid van een onderhandse executoriale verkoop van een met hypotheek bezwaard goed enkel op grond van een overeenkomst tussen de hypotheekgever, c.q. de curator in het faillissement van de hypotheekgever, en de hypotheekhouder. Voor iedere onderhandse executoriale verkoop door de hypotheekhouder is (naast andere vereisten) in ieder geval steeds de toestemming van de voorzieningenrechter nodig (art. 3:268 lid 2 BW). Hoewel de introductie van een ruimere onderhandse executiebevoegdheid ten behoeve van de hypotheekhouder in de literatuur wel is bepleit, ${ }^{6}$ staat naar geldend recht vast dat een onderhandse verkoop door de hypotheekhouder enkel met toestemming van de hypotheekgever geen executoriale verkoop oplevert. Hierdoor vindt geen zuivering plaats (vgl. art. 3:273 BW) en kunnen belanghebbenden geen verzoek doen tot het vaststellen van een rangregeling. ${ }^{7}$ Ook missen bepalingen als de art. 7:19 en 3:264 BW toepassing. Een en ander geldt onverkort indien de curator in eigen naam (in opdracht van of met toestemming van de hypotheekhouder) het hypotheekrecht zou willen uitoefenen, zonder dat aan de dwingendrechtelijke voorschriften daarvoor wordt voldaan. Het oordeel van de Hoge Raad in de beschikking Staatssecretaris van Financiën/X dat in een dergelijk geval sprake is of kan zijn van de uitoefening van het recht van parate executie door de hypotheekhouder, ook indien niet is voldaan aan de vereisten die art. 3:268 lid $2 \mathrm{BW}$ stelt, is - hoe men het ook wendt of keert - in strijd met de wet. In de literatuur zijn dappere pogingen gedaan de uitspraak van de Hoge Raad overeind te houden, maar wij vrezen dat die pogingen niet veel uithalen. Zo heeft Steneker de verklaring dat oneigenlijke lossing een wijze van executie van het pand- of hypotheekrecht is, gezocht

'in het feit dat de curator ook een eigen executiebevoegdheid heeft. Het executoriale karakter van de verkoop is kennelijk meer gebaseerd op die eigen executiebevoegd-

6. Vgl. N.S.G.J. Vermunt, Enkele knelpunten bij pand, hypotheek en beslag, in: S.C.J.J. Kortmann e.a. (red.), Onderneming en 10 jaar nieuw Burgerlijk Recht, Deventer: Kluwer 2002, p. 345 en M.L.M. Bindels, J.M. Rommes \& M. van Wingerden, Uitwinningsperikelen, een praktische beschouwing van de mogelijkheden om hypothecair onderpand te gelde te maken, in: J.G. Princen \& I. Spinath (red.), Faillissement en vastgoed, Deventer: Kluwer 2012, p. 120.

7. Vgl. MvA II, Parl. Gesch. Boek 3 BW, p. 825 en MvA II, Parl. Gesch. Boek 3 BW (Inv. 3, 5 en 6), p. 1343. 
heid van de curator dan op een afgeleide bevoegdheid tot onderhandse executie op grond van art. 3:268 lid 2 BW (...). De gedachte zou dan zijn dat hypotheekhouder en curator kunnen overeenkomen dat de curator zijn eigen executiebevoegdheid aanwendt ten behoeve van de pandof hypotheekhouder en dat de verkoop in dat geval kan worden aangemerkt als een executie van dat pand- of hypotheekrecht.'8

Wij hebben moeite deze redenering te volgen. De verklaring die Steneker voor de nieuwe benadering van oneigenlijke lossing geeft, is in wezen een bevestiging dat de oude benadering de juiste was. De eigen executiebevoegdheid van de curator is gegrond op art. 101 of $176 \mathrm{Fw}$ en heeft met de uitwinning van het pand- of hypotheekrecht hoegenaamd niets van doen. In de overwegingen van de Hoge Raad vinden wij ook geen aanknopingspunten dat de Hoge Raad een dergelijke hybride figuur op het oog zou hebben gehad. Van Bergen tracht de beschikking van de Hoge Raad inzake Staatssecretaris van Financiën/X af te doen via 'het zuiver fiscale karakter van het betreffende geschil dat aan de Hoge Raad voorlag' . ${ }^{9}$ Het moge zo zijn dat de Hoge Raad had te oordelen over het al dan niet van toepassing zijn van de (hierna nog te noemen) verleggingsregeling voor de omzetbelasting, een fiscale kwestie, maar dat neemt niet weg dat de Hoge Raad in deze beschikking tracht een op het arrest ING/Hielkema q.q. gebaseerde civielrechtelijke verklaring te geven van oneigenlijke lossing. De desbetreffende overwegingen van de Hoge Raad wekken niet de indruk fiscaal te zijn gekleurd. Bovendien verwijst de Hoge Raad in het arrest ING/Hielkema q.q. reeds mede naar hypotheek, waardoor op zijn minst de indruk wordt gewekt dat de civielrechtelijke analyse bij hypotheek in de optiek van de Hoge Raad dezelfde is of zou moeten zijn als bij pand.

\section{Preventief rechterlijk toezicht?}

Ten aanzien van een eigenlijke lossing bepaalt art. 68 lid 2 Fw dat de curator machtiging van de rechter-commissaris behoeft. Voor een onderhandse executoriale verkoop door de curator op de voet van art. 101 of art. $176 \mathrm{Fw}$ is blijkens deze bepalingen de toestemming van de rechter-commissaris vereist. Met betrekking tot een oneigenlijke lossing wordt in de wet niets bepaald en, indien men de nieuwe benadering van de Hoge Raad volgt, is geen van de genoemde regelingen die uitgaan van een vorm van preventief rechterlijk toezicht, dwingendrechtelijk van toepassing. Daardoor zou een oneigenlijke lossing slechts onderworpen zijn aan het algemene toezicht van de rechter-commissaris ingevolge art. $64 \mathrm{Fw}$, hetgeen ons ongelukkig en ongewenst voorkomt. Overigens verwachten wij niet dat de Hoge Raad het hierbij zal laten. Dat in de optiek van de Hoge Raad bij een onderhandse verkoop van een met hypotheek bezwaard goed ook zonder toestemming van de voorzieningenrechter sprake kan zijn van een executoriale verkoop, betekent niet dat die toestemming steeds achter-

8. A. Steneker, Uitbestede executie, WPNR 7033 (2014), p. 914 en 918.

9. S.J.L.M. van Bergen, Oneigenlijke lossing als vorm van parate executie (?!), WPNR 7033 (2014), p. 919 en 925-926. wege zou mogen blijven. Wanneer men de hobbel van art. 3:268 lid 5 BW heeft genomen, ligt het onzes inziens echter meer voor de hand haar te vervangen door voorafgaande toestemming van de rechter-commissaris. De eigenlijke en oneigenlijke lossing worden dan in zoverre weer op één lijn gesteld.

\section{Verleggingsregeling omzetbelasting}

De aanleiding voor de procedures die hebben geleid tot de hiervoor besproken oordelen in ING/Hielkema q.q. en Staatssecretaris van Financiën/X, was de vraag of in voorkomend geval de verleggingsregeling voor de omzetbelasting van art. 12 lid 4 van de Wet op de omzetbelasting 1968 (Wet OB 1968) jo. art. $24 \mathrm{ba}$ lid 1, aanhef en onder d, van het Uitvoeringsbesluit omzetbelasting 1968 (Uitv.besl. OB 1968) op een oneigenlijke lossing van toepassing is. In de nieuwe benadering van de Hoge Raad kan er geen twijfel over bestaan dat zulks het geval is. De verleggingsregeling beoogt te ontkomen aan de gevolgen van het Rentekas-arrest. ${ }^{10}$ Uit dit arrest (en het systeem van de Wet OB 1968) volgt dat een pand- of hypotheekhouder zich bij executie mag verhalen op het volledige bedrag dat de koper uit hoofde van de koopovereenkomst voor het aan hem verkochte goed verschuldigd is, met inbegrip van het bedrag van de te zijnen laste gebrachte, (mogelijk) op de levering verschuldigde omzetbelasting. Anders dan het geval is bij de heffing van overdrachtsbelasting bij de executieverkoop van een onroerende zaak (zie art. 16 van de Wet op belastingen van rechtsverkeer), is omzetbelasting immers verschuldigd door de hypotheekgever, i.e. de ondernemer wiens goed wordt verkocht, en niet door de hypotheekhouder of de executiekoper. De regel van het Rentekas-arrest werd onverkort van toepassing geacht op een oneigenlijke lossing. ${ }^{11}$ De enige manier om hieraan te ontkomen, was het opnemen van een verleggingsregeling, waarbij de heffing van omzetbelasting van de ondernemer (pand- of hypotheekgever) naar de executiekoper wordt verlegd. Dit is in art. 24 ba lid 1 , aanhef en onder d, Uitv.besl. OB 1968 gebeurd ingeval 'een in zekerheid gegeven roerende of onroerende zaak dan wel een recht waaraan een onroerende zaak is onderworpen, wordt geleverd aan een ondernemer tot executie van die zekerheid'. Deze omschrijving blinkt niet uit in helderheid, maar volgens de toelichting op deze bepaling is hieronder tevens een oneigenlijke lossing begrepen, en in de nieuwe benadering van de Hoge Raad kan daarover geen twijfel bestaan. In de 'oude' benadering zou de verleggingsregeling toepassing missen; noch bij eigenlijke lossing, noch bij oneigenlijke lossing zou dan sprake zijn geweest van de levering tot executie van een zekerheid. Dat het 'raar zou zijn als de BTW-verleggingsregeling via oneigenlijke lossing zou kunnen worden omzeild', zoals Steneker stelt, ${ }^{12}$ zien wij niet. De verleggingsregeling mist immers ook in andere gevallen, waarin geen sprake is van de uitoefening van een pand- of hypotheekrecht, toepassing. Dit geldt overigens ook

10. HR 6 mei 1983, NJ 1984/228 m.nt. WMK.

11. Vgl. voor hypotheek HR 13 maart 1987, NJ 1988/556 m.nt. WMK (Ontvanger/Spruijt q.q.) en voor pand Hof Leeuwarden 29 mei 2002, JOR 2002/181 m.nt. Faber (Ontvanger/Overes q.q.).

12. Steneker, WPNR 7033 (2014), p. 913. 
voor de situatie buiten faillissement, bijvoorbeeld wanneer de pand- of hypotheekgever zelf tot lossing overgaat, of wanneer de pand- of hypotheekhouder, hoewel hij tot uitwinning bevoegd is, met de pand- of hypotheekgever overeenkomt dat deze het desbetreffende goed vrijwillig zal verkopen. Men kan in deze gevallen toch moeilijk van het 'omzeilen' van de verleggingsregeling spreken. Verder merken wij op dat de verleggingsregeling ook om geheel andere redenen buiten toepassing blijft, bijvoorbeeld omdat de koper aan wie het desbetreffende goed executoriaal wordt verkocht, zelf geen ondernemer voor de omzetbelasting is.

\section{Tot slot}

De Hoge Raad balanceert met zijn uitspraken ING/Hielkema q.q. en Staatssecretaris van Financiën/X op een slap koord. De wijze waarop de Hoge Raad de oneigenlijke lossing kwalificeert, staat op gespannen voet met de afspraken die tussen de curator en de pandhouder respectievelijk hypotheekhouder plegen te worden gemaakt. De eerste uitspraak is technischjuridisch bezien niet onjuist, maar het oordeel waartoe de Hoge Raad komt, achten wij vergezocht; in de tweede uitspraak geeft de Hoge Raad een oordeel dat in strijd is met dwingend recht. Het lijkt erop dat het doel (het van toepassing doen zijn van de verleggingsregeling voor de omzetbelasting op een oneigenlijke lossing) hier de middelen heiligt. Ons overtuigt deze jurisprudentie echter geenszins en wij zijn benieuwd welke draai de Hoge Raad in toekomstige uitspraken aan deze jurisprudentie zal geven. 